\title{
PROJETO DE REVITALIZAÇÃO DO CINE TEATRO PLAZA Conforto acústico
}

\author{
Ana L. S. Alves'; Anamaria M. M. Farah ${ }^{1}$; Andressa G. S. Caetano'; Daniel G. \\ Bertusso $^{1}$; Felipe A. G. Zanoni ${ }^{1}$; Gabriel Belther ${ }^{1}$; Gabriel S. da Silva ${ }^{1}$; Gabriel Z. \\ Tomadon'; lago R. M. Valejo'; Italo G. S. Madeira'; Jeselay H. C dos Reis ${ }^{1}$; João G. \\ O. Marques ${ }^{1}$; Luana Manchenho'; Lucas R. de Souza ${ }^{1}$; Marcelo A. da Silva ${ }^{1}$; \\ Marina N. Furukawa ${ }^{1}$; Matheus Schoenberg ${ }^{1}$; Raquel de O. Collet ${ }^{1}$; Vinicius G. P. de \\ Souza'; Vitor H. V. Brandolim¹. \\ ${ }^{1}$ Universidade Estadual de Maringá (UEM), DEC. \\ PET Engenharia Civil UEM, Maringá, Paraná.
}

Palavras-chave: Espelhos acústicos; tempo de reverberação; absorção acústica; som.

\section{Introdução}

O Cine Teatro Plaza, da cidade de Maringá-PR, de posse da Prefeitura, em 2009, foi interditado pelo Corpo de Bombeiros por falta de alguns requisitos de segurança a incêndios e conforto (acessibilidade). Segundo o meio artístico, era o teatro com melhor acústica da cidade e bastante utilizado pela comunidade acadêmica da UEM, pela falta de auditórios grandes na mesma. Então, buscando desenvolver uma pesquisa em grupo, o PET Civil UEM mobilizou-se para elaborar um projeto de revitalização.

O projeto de conforto acústico, uma das partes de projeto como um todo, em sua concepção, buscou manter a acústica do Cine Teatro Plaza, considerada ótima - tal fato se deve muito ao piso de madeira existente -, o que foi uma exigência da Prefeitura de Maringá. Como se trata de um Cine Teatro, as soluções foram buscadas para que se adequassem da melhor forma possível a apresentações teatrais (foco para a realização do projeto), musicais, e de cinema, de modo a preservar sua utilização anterior, que é histórica para a cidade. 


\section{SYVIIVNPET}

Tratar acusticamente um ambiente consiste em dar boas condições de audibilidade, através das acústicas dos revestimentos e geometria internos e também em bloquear os ruídos externos e os produzidos internamente que podem atrapalhar o entorno (CARVALHO, 2006). Então, os objetivos finais do estudo eram definir o layout do teatro (volume) e os materiais a serem utilizados, para a obtenção de um bom tempo de reverberação, que segundo Rigden (1985) é definido como o tempo correspondente ao decaimento em $60 \mathrm{~dB}$ na intensidade do som reverberante.

\section{Metodologia}

As atividades para a revitalização do Cine Teatro Plaza foram divididas na fase de inventário, para o levantamento da realidade do teatro, através de visitas técnicas e documentos da prefeitura - nesta etapa que foi definida a necessidade do estudo específico de conforto acústico. E também na fase de elaboração do projeto de revitalização, compreendida em:

- Definição da problemática do projeto (através de revisão bibliográfica, principalmente em normas técnicas, no caso NBR 10152, NBR 15575, NBR 12179:1992);

- Definição das soluções que melhor se adequam para o projeto (contando também com ajuda de profissionais e uma professora do Departamento de Engenharia Civil (DEC) da UEM da área de conforto);

- Elaboração de detalhes do projeto em cima do projeto arquitetônico do Cine Teatro (espelhos refletores no forro e materiais);

A fim de melhorar a acústica e amplificar o som emitido no palco, foram dimensionados espelhos acústicos. Para o traçado dos mesmos, a Prof. Dra Aline Lisot, que ministra a disciplina de "Conforto Ambiental para Engenharia Civil" para o $4^{\circ}$ ano, forneceu suas notas de aula e orientações, exemplificado na figura 1. Após dimensionados, foi conferida a validade de alcance e frequência dos mesmos. Também definido os materiais e a volumetria da sala a fim de atingir um tempo de reverberação adequado. 
Figura 1: Passo a passo do dimensionamento dos espelhos.

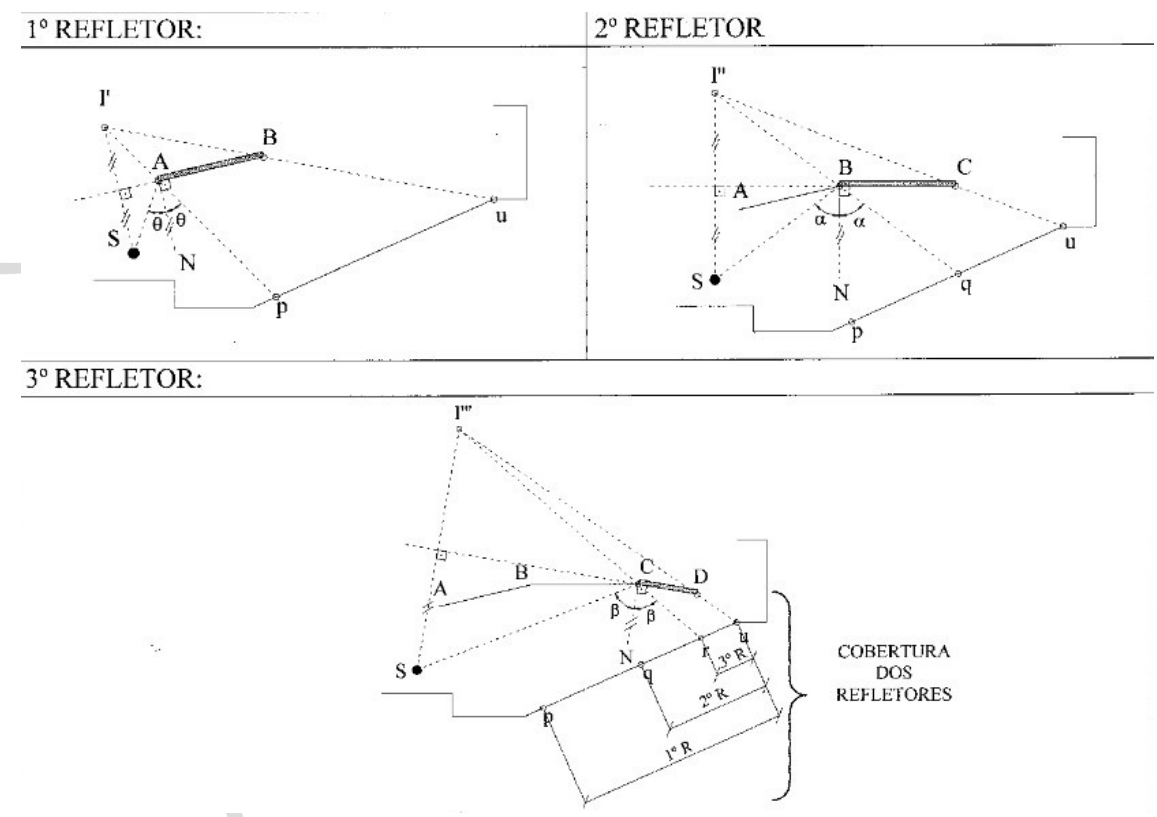

Fonte: Notas de aula, 2018.

\section{Resultados e discussão}

Os espelhos acústicos obtidos após o traçado foram:

Figura 2: Espelhos refletores e absorsores.

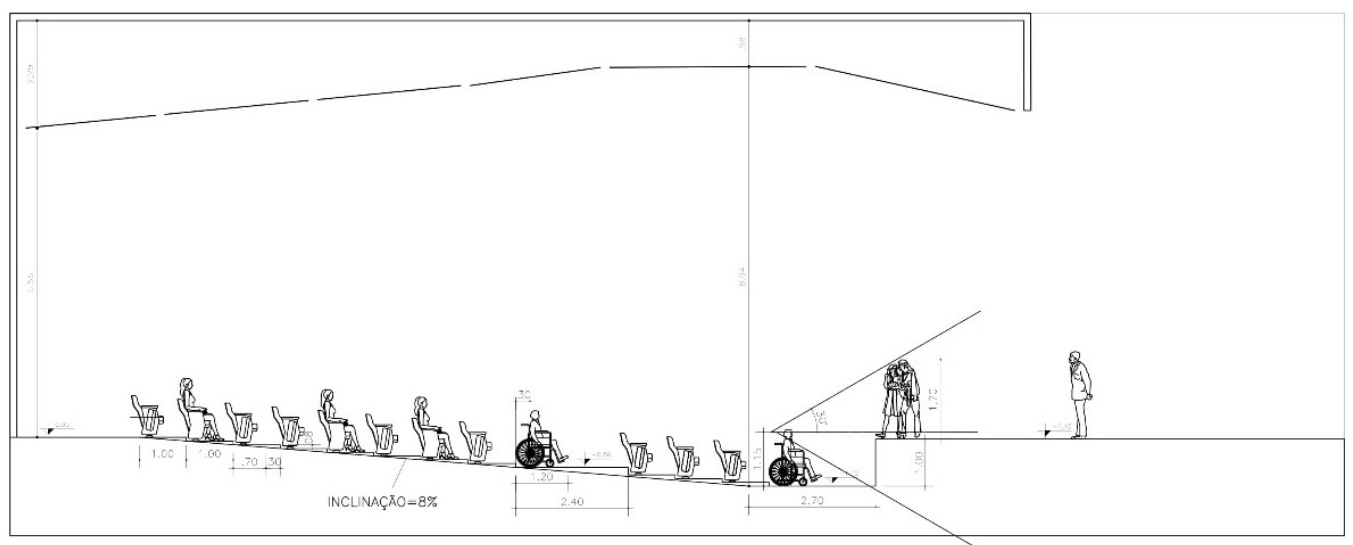

Fonte: Autores, 2018.

Os três espelhos iniciais (da direita para a esquerda) são refletores, projetados de modo que o primeiro refletisse o som para a plateia inteira, o segundo da metade para o fundo e o terceiro para um quarto da plateia no fundo. Os demais painéis não têm 
função de amplificar e distribuir o som, mas estética. Os espelhos refletores projetados podem ser analisados quanto às condições de audição dos sons refletidos conforme os critérios da Tabela 1.

Tabela 1: Critérios de análise para espelhos refletores planos

\begin{tabular}{|c|c|}
\hline Diferença de caminhamento sonoro (m) & Condições de audição \\
\hline$<8,5$ & Excelente para fala e música \\
\hline $8,5-12,2$ & Bom para fala, médio para música \\
\hline $12,2-15,2$ & Regular \\
\hline $15,2-20,7$ & Ruim \\
\hline 20,7 & Percepção de eco \\
\hline
\end{tabular}

Fonte: Notas de aula.

No projeto dos espelhos do Cine Teatro Plaza buscamos excelentes condições de audição para fala e música, ou seja, uma diferença de caminhamento sonoro menor que $8,5 \mathrm{~m}$ em todos os espelhos. A diferença de caminhamento sonoro é dada pela Equação (1),

$$
\text { dif. de caminhamento }=a+b-c
$$

onde "a" é a distância do ponto de emissão do som até um ponto do espelho, "b" é a distância do ponto do espelho até o ponto final de recepção do som e "c" é a distância entre o ponto de emissão e o ponto de recepção final do som.

$\mathrm{Na}$ análise realizada nos espelhos traçados, foram considerados dois pontos em cada espelho, um no início (P1) e um no final (P2), da direita para a esquerda. Os resultados da análise estão na Tabela 2.

Tabela 2: Resultados da análise dos espelhos refletores

\begin{tabular}{|c|c|c|}
\hline Espelho & $\begin{array}{c}\text { Diferença de caminhamento P1 } \\
(\mathbf{m})\end{array}$ & $\begin{array}{c}\text { Diferença de caminhamento P2 } \\
\mathbf{( m )}\end{array}$ \\
\hline 1 & 7,6610 & 4,4657 \\
\hline 2 & 6,2799 & 3,9214 \\
\hline 3 & 1,1548 & 3,7266 \\
\hline
\end{tabular}

Fonte: Elaborado pelos autores. 
Em acústica, define-se a reverberação como a persistência do som no ambiente (RIGDEN, 1985). Para o cálculo do tempo de reverberação, há várias relações empíricas. A utilizada para o estudo foi a de Sabine, um pouco mais simplista em comparação às outras, dada pela Equação (2),

$$
T=0,16 \cdot \frac{V}{A}
$$

onde "V" é o volume da sala, em metros cúbicos $\left(\mathrm{m}^{3}\right)$ e "A" é a absorção da superfície, em metros quadrados $\left(\mathrm{m}^{2}\right)$ ou sabines.

O volume médio da sala foi de $5316 \mathrm{~m}^{3}$. Para chegar no TR final, com base no arquitetônico, foram medidas as áreas e os materiais de cada parte do teatro foram sendo definidos, controlando para que se obtivesse um TR (tempo de reverberação) adequado. Os tempos de reverberação para cada frequência estão na Tabela 3.

Tabela 3: Tempos de reverberação resultantes para cada frequência

\begin{tabular}{|c|c|c|c|c|c|c|}
\hline Frequência (Hz) & 125 & 250 & 500 & 1000 & 2000 & 4000 \\
\hline Tempo de reverberação (s) & 2,2 & 1,6 & 1,3 & 1,1 & 1,1 & 1,1 \\
\hline
\end{tabular}

Fonte: Elaborado pelos autores.

O tempo de reverberação ideal é igual a $1,3 \mathrm{~s}$ em $500 \mathrm{~Hz}$ de acordo com o gráfico fornecido no livro do Bistafa (2011). A correção do TR ideal para as outras frequências pode ser feita multiplicando o valor de 1,3 s pelos coeficientes de correção obtidos na norma ABNT NBR 12179:1992. Para a frequência de $125 \mathrm{~Hz}$, pode-se usar o coeficiente 1,48; para $250 \mathrm{~Hz}, 1,15$; para $1000 \mathrm{~Hz}, 2000 \mathrm{~Hz}$ e $4000 \mathrm{~Hz}$ pode-se usar o coeficiente 0,85 . Desta forma, o tempo de reverberação ideal em cada frequência será o apresentado a seguir, na Tabela 4.

Tabela 4: Tempos de reverberação ideais para cada frequência

\begin{tabular}{|c|c|c|c|c|c|c|}
\hline Frequência (Hz) & 125 & 250 & 500 & 1000 & 2000 & 4000 \\
\hline Tempo de reverberação (s) & 1,9 & 1,5 & 1,3 & 1,1 & 1,1 & 1,1 \\
\hline
\end{tabular}

Fonte: Notas de aula. 
O tempo de reverberação ideal às vezes não é 100\% atendido nas frequências mais graves. Isso não é uma grande falta já que o ser humano tem uma grande limitação de audição nessas frequências.

\section{Conclusões}

O trabalho em grupo, visitas ao local, estudo da Literatura e o contato com professores e profissionais da área contribuíram para o conhecimento dos petianos envolvidos, que tiveram contato com detalhes de um projeto acústico e com o ambiente teatral. Em comparação com a norma NBR 12179:1992, o tempo de reverberação médio do Cine Teatro Plaza $(1,40 \mathrm{~s})$ difere em $0,07 \mathrm{~s}$ do considerado ótimo, ou seja, 5,3\%, considerado bom, validando a escolha da geometria da sala, dos espelhos acústicos e principalmente dos materiais escolhidos.

Apesar de todos resultados satisfatórios, era possível obter um melhor detalhamento, não possível pelo fator tempo, mas que faz possível o projeto de revitalização ser levado a diante.

\section{Referências}

ABNT (Associação Brasileira de Normas Técnicas). NBR 10152: Níveis de ruído para conforto acústico - Procedimento. Rio de Janeiro, 1987.

NBR 12179: Tratamento Acústico em Recintos Fechados. Rio de Janeiro, 1992.

BISTAFA, S. R. Acústica aplicada ao controle do ruído. São Paulo: Edgard Blucher, 2011.

CARVALHO, R. P. Acústica Arquitetônica. Brasília: Ed. Thesaurus, 2006.

RIGDEN, J.S. Physics and the Sound of Music. 2nd ed. Wiley, New York, USA, 1985.

LISOT, A. Notas de aula, Departamento de Engenharia Civil, Universidade Estadual de Maringá, Maringá, 2018. 